\title{
A PLURALIDADE DO ATOR NAS FRONTEIRAS DO BOLPEBRA
}

\author{
THE HETEROGENEITY OF ACTOR AT THE BORDERS BOLPEBRA
}

\section{LA PLURALIDAD DEL ACTOR EN LAS FRONTERAS DEL BOLPEBRA}

Emilson Ferreira de Souza

Mônica da Silva Cruz

\begin{abstract}
Resumo: Este artigo avalia a pluralidade de esquemas de ação incorporados por seringueiros do BOLPEBRA, região compreendida entre Bolívia-Pando, Peru-Madre de Dios, Brasil-Acre. Os seringueiros serão entendidos neste trabalho como sujeitos sócio-históricos. As reflexões seguem o aporte teórico-metodológico da Teoria da Ação, proposta por Bernard Lahire (2002). Metodologicamente, avaliam-se dois depoimentos e algumas imagens do universo dos seringueiros habitantes do espaço conhecido como a Tríplice Fronteira do BOLPEBRA. A coleta dos dados realizou-se por meio de pesquisa in loco, no ano de 2006, durante os meses de julho e novembro. Seguem-se ainda os estudos de autores como Tocantins (2003), Souza (2001), Bauman (2005) e outros. Os dados mostram que os seringueiros não se percebem como capazes de atuarem em novas cenas, diante da ameaça de perderem sua terra. Os relatos sugerem que esses sujeitos não agem sempre com coerência, dado a possível diversidade de elementos incorporados em razão da pluralidade de suas experiências socializadoras.
\end{abstract}

Palavras-chave: BOLPEBRA. Ator plural. Seringueiros.

\begin{abstract}
This article evaluates the plurality of action incorporated by rubber tappers of BOLPEBRA (region between Pando - Bolivia, Peru, Madre de Dios, Acre, Brazil). These workers are defined in this study as socio- historical subjects schemes. The reflections follow the theoretical and methodological support of the Theory of Action, proposed by Bernard Lahire (2002). Methodologically, we evaluate two testimonies and pictures of the universe of the some tappers, inhabitants of the area known as the Triple Frontier of BOLPEBRA. Data collection took place through research on the spot, in 2006 , during the months of July and November. Still follow the studies of authors such as Tocantins (2003), Souza (2001), Bauman (2005) and others. The data show that the tappers do not perceive themselves as able to act in new scenes, with the threat of losing their land. These reports suggest that these individuals do not always act with consistency, given the diversity of possible elements incorporated because of the plurality of their socializing experiences.
\end{abstract}

Keywords: BOLPEBRA. Actor plural. Tappers.

Resumen: En este artículo se evalúa la pluralidad de acción incorporado por los caucheros de Bolpebra, definidos en este estudio como los esquemas de los sujetos socio-históricos. Las reflexiones siguen el soporte teórico y metodológico de la Teoría de la Acción, propuesto por Bernard Lahire ( 2002 ). Metodológicamente, evaluamos dos testimonios e imágenes del universo de algunos extractores, habitantes de la zona conocida como la Triple Frontera de Bolpebra (región entre Pando - Bolivia, Perú, Madre de Dios, Acre, Brasil). La recolección de datos se llevó a cabo através de la investigación sobre el terreno, en 2006, durante los meses de julio y noviembre. Aún así seguir los estudios de autores como Tocantins (2003), Souza (2001), Bauman (2005) y otros. Los datos muestran que los recolectores no perciben a sí mismos como capaces de actuar en nuevas escenas, con la amenaza de perder sus tierras. Estos informes sugieren que estos individuos no siempre actúan con coherencia, dada la diversidad de posibles elementos incorporados debido a la pluralidad de sus experiencias de socialización .

Palabras clave: BOLPEBRA. Plural Actor. Tappers.

\section{INTRODUÇÃO}

Neste trabalho, discute-se a pluralidade das ações dos seringueiros da Tríplice Fronteira BOLPEBRA - espaço compreendido entre os estados da Bolívia-Pando, Peru-Madre de Dios, Brasil-Acre. A área chamada BOLPEBRA, nesta pesquisa, segue o sentido que lhe foi atribuído a partir do início da construção da
Rodovia Interoceânica, em 2009, referindo-se ao campo delimitado pelos três países. Nessa região fronteiriça, culturas, políticas e histórias se bifurcam, fazendo emergir uma situação identitária única e instigante. O referencial teórico mobilizado pauta-se na teoria do Ator Plural, de Bernard Lahire (2002, p. 31), para o qual "um ator plural é produto da experiência

\footnotetext{
*Artigo recebido em agosto de 2013

Aprovado em outubro de 2013
} 
de socialização em contextos sociais múltiplos e heterogêneos".

$O$ interesse pela pesquisa surge da observação de que, em contexto de fronteira, a própria localização geográfica onde os sujeitos habitam propicia uma espécie de pluralidade de ações e identidades, pois, conforme Pesavento (2002, p.35), as fronteiras, "antes de serem marcos físicos ou naturais, são, sobretudo, elementos simbólicos", marcos de referência mental que guiam a percepção da realidade. Esses limites são produto de uma capacidade de representar o mundo por meio de outro mundo, de apreender sinais por meio dos quais os homens percebem e qualificam a si próprio, ao corpo social, ao espaço e ao próprio tempo. As fronteiras são acima de tudo representações culturais, são construções de sentido, são elementos que estabelecem classificações, hierarquias e limites, direcionando olhares e apreciações sobre o mundo. $A$ priori, a fronteira é um perímetro que "limita e separa, e que aponta sentidos socializados de reconhecimento" afirma Pesavento (2002, p.36).

Em pesquisa desenvolvida no Estado do Acre, observaram-se a pluralidade de culturas e a heterogeneidade de identidades dos povos que antes exploravam os seringais da Fronteira do BOLPEBRA. Neste trabalho, reúnem-se informações sobre a situação identitária desses sujeitos (antes reconhecidos como "seringueiros do BOLPEBRA") a partir de um material que resultou no Documentário La rota del pacífico ${ }^{1}$. A documentação foi elencada principalmente por meio do registro videográfico, obedecendo a uma metodologia identificada por France (1998) como antropologia fílmica, a qual consiste em fazer a observação instrumentalizada com aparelhos de gravação, audiovisual e montagem, adaptadas à realização de uma pesquisa que acontece no próprio ambiente em que se encontram as pessoas avaliadas.

Para essa empreitada, mobilizam-se, a seguir, alguns direcionamentos sobre a teoria do Ator Plural, proposta por Bernard Lahire (2002).

\section{ATOR PLURAL: BREVES NOTAS SOBRE OS ATORES DA FRONTEIRA DO BOLPEBRA}

Para Lahire (2002, p.10), a realidade social inscrita em cada ator singular é sempre muito complexa. Em sua perspectiva, o sentido do termo "ator" deve ser sempre dimensionado em relação a uma série de palavras que remetem à ideia de "ação", a exemplo dos vocábulos "ato", "atividade", "reativar", evitando, assim, o sentido clássico da metáfora teatral.

O autor questiona as premissas da unicidade do ator, afirmando não haver "nenhuma evidência" nesse sentido (LAHIRE, 2002, p. 20). Não crê, como muitos antropólogos, que uma sociedade, uma tribo ou uma comunidade, por exemplo, pode ser uma realidade homogênea. Mas adverte que há, por outro lado, um risco em crer em uma espécie de pulverização de papéis, de comportamentos, de ações e reações sem nenhuma espécie de relação entre elas (LAHIRE, 2002, p.22). Para o estudioso, cada ator agrega, ao longo de sua existência, um conjunto de "esquemas de ação", na forma de "repertórios", disponíveis em distintos contextos sociais. Esses esquemas permitem que o sujeito desempenhe, em diferentes situações, ações que fazem dele um ator plural. Desse modo, é possível ter identidades plurais, desde que os contextos sociais e históricos permitam essa pluralidade.

O ator plural, uma vez colocado, simultânea ou sucessivamente, dentro de uma pluralidade de mundos sociais não homogêneos, por vezes até contraditórios, apresenta práticas heterogêneas que variam de acordo com o contexto social (LAHIRE, 2002, p.31). Assim sendo:

\begin{abstract}
Os repertórios de esquemas de ação (de hábitos) são conjuntos de sínteses de experiências sociais que foram construídas/incorporadas durante a socialização anterior nos âmbitos sociais limitados/delimitados, e aquilo que cada ator adquire progressivamente e mais ou menos completamente são tanto hábitos como sentidos da pertença contextual [...] (LAHIRE, 2002, p.37).
\end{abstract}

As observações do autor também apontam que "a coerência dos hábitos ou esquemas de ação (esquemas sensório-motores, esquemas de percepção, de apreciação, de avaliação etc. )" que cada ator pode ter interiorizado, depende, portanto, da coerência dos princípios de socialização nos quais esteve inserido (LAHIRE, 2002, p.31).

No capítulo intitulado "Os determinantes da ação", Lahire (2002, p.46) destaca uma série de aspectos que pode ter um peso sobre a ação. Assim, avalia, por exemplo, o peso que presente e passado têm sobre a ação do ator; as situações de crise e as implicações que o contexto imprime sobre o ator e suas ações.

Em relação às situações de crise, Lahire (2002, p. 49) afirma:

Crises de adaptação, crises da ligação de cumplicidade ou de conivência ontológica entre o incorporado e a situação nova [...] essas situações são multiformes e caracterizam a condição humana nas sociedades complexas, plurais e em transformação.

Para ele, essas situações não ocorrem isoladamente e combinam-se, agravando preocupações, gerando sofrimentos, interrogações e reflexões sobre a ação, tornando a existência muitas vezes opressiva.

Já em relação ao contexto, explica:

As situações sociais (das mais formais e institucionais às mais informais) nas quais vivemos constituem verdadeiros ativadores de resumos de experiências incorporados que são nossos "esquemas de ação" (no sentido amplo do termo) ou nossos hábitos e que de- 
pendemos assim fortemente desses contextos sociais (institucionais ou não institucionais) que tiram de nós certas experiências e deixam outras em estado de gestação ou de vigília. Mudar de contexto (profissional, conjugal, familiar, religioso, político...) é mudar as forças que agem sobre nós (LAHIRE, 2002, p.59).

Em situação de fronteira, os seringueiros deveriam constituir uma pluralidade de ações, pois na fronteira, muitas identidades se cruzam e se desfazem, resignificam-se, em confronto com outras, e exigem do ator uma plasticidade em relação à sua forma de vida. As fronteiras, conforme já afirmado, são mais que um espaço físico, são nichos complexos de atuação de uma diversidade de ações, as quais devem, de algum modo, ser processadas pelos atores que lá habitam.

$O$ perfil dos seringueiros da Fronteira do BOLPEBRA segue mais ou menos o seguinte padrão: em geral, são pessoas ligadas ao campo, à ruralidade; têm situação econômica muito limitada e as bases de sobrevivência é, predominantemente, a natureza, pois retiram seu sustento da terra, da floresta.

Em conversa com alguns deles, observou-se como esses indivíduos se percebem enquanto atores. Notou-se como temem se deslocarem de seu universo e assumirem outras identidades, conforme afirmaram em depoimentos, avaliados a seguir, no item três. Antes de se verificarem essas declarações, para melhor contextualização dessas falas, apresentam-se alguns aspectos históricos e políticos que constituem a saga dos seringueiros no BOLPEBRA.

\subsection{Situando a história dos seringueiros da Fronteira do BOLPEBRA}

Segundo Tocantins (2003), até início do séc. XIX encontravam-se somente índios na floresta acreana. Os amazonenses e paraenses foram os primeiros brasileiros "civilizados" a explorar a região, atraídos pela hevea brasiliensis, que produz o látex, a borracha.

Com a demanda do mercado internacional pela borracha, a notícia se espalhou pelo nordeste brasileiro. Logo vieram, para essa parte da floresta, nordestinos de todos os estados, com máxima presença de cearenses, "ao sabor da aventura, da audácia em explorar lugares não sabidos, cheios de perigos de vida: doenças, ataques de índios e de animais" (TOCANTINS, 2003, p. 16). Segundo Paula (1991), esses sujeitos receberam várias denominações ao longo de sua estada no espaço conhecido hoje como Acre. Passaram a ser tratados primeiro como "brabos", quando migraram do Nordeste para Amazônia, depois, quando apreenderam o ofício do seringal, receberam o nome de "mansos". Durante a segunda guerra, período que novamente nordestinos migraram para Amazônia, foram chamados de "arigós". Quando começaram a serem expulsos dos seringais, nos anos de 1970, pelos "paulis- tas", receberam a denominação de "acreanos" (PAULA, 1991).

O francês Charles Marie de La Condamine, em visita aos índios do Alto Amazonas, viu-os utilizando o leite vegetal da seringueira para diversas finalidades. Ele relatou para Academia de Ciências de Paris sua descoberta e os cientistas ficaram, então, impressionados com a ideia da resina amazônica. Anos depois, o inglês Thomas Hancock, e o americano Charles Goodyer descobriram o processo de vulcanização, com patentes registradas em 30/05/1844 e 15/06/1844, respectivamente.

O comércio da borracha, que se ativado um século
antes estaria condenado ao marasmo, beneficia-se
do progresso tecnológico e é arrastado pela última
etapa da revolução industrial. McIntosch descobre a
impermeabilização. Goodyear, em 1844, cria o siste-
ma de vulcanização. As fábricas americanas e euro-
péias diversificavam suas linhas de produtos: bolas,
cintos, espartilhos, suspensórios, ligas, molas para
portas, capas impermeáveis, tapetes, cadeiras, sa-
cos para água quente, salva-vidas. Uma indústria de
miudezas domésticas para rápido consumo. Depois,
pneumáticos para os veículos (SOUZA, 2001, p. 178).

A revolução industrial liderada pela Inglaterra, França e Estados Unidos impulsionou de forma acentuada o comércio mundial da borracha, pois a vulcanização permitiu a troca das rodas de ferro das carruagens pelas de pneu. Logo depois vieram os carros, as bicicletas etc. Assim, o Acre torna-se o centro produtor da matéria prima, a borracha, disputada pelas maiores nações industrializadas. O preço da borracha sobe em demasia, o que fez, cada vez mais, atrair trabalhadores para os rincões da floresta.

Enquanto o colono italiano se desloca de Gênova à mais remota fazenda de São Paulo, paternalmente assistido pelos nossos poderes públicos, o cearense efetua, à sua custa e de todo desamparado, uma viagem mais difícil, em que os adiantamentos feitos pelos contratadores insaciáveis, inçados de parcelas fantásticas e de preços inauditos, o transformam as mais das vezes em devedor para sempre insolvente (CUNHA, 1976, p. 132).

A ocupação do território acreano pelos nordestinos brasileiros se deu em duas frentes: primeiro adentraram as regiões do vale dos Rios Acre e Purus e depois o vale do Rio Juruá.

Até 1870 , o espaço acreano era ocupado por populações indígenas, por algumas centenas de peruanos que exploravam a extração do caucho, no vale do Alto Purus e por alguns bolivianos no vale do Rio Acre, que começaram a explorar as gomas naturais.

Os seringalistas subiam os rios à procura de áreas com maior concentração de árvores de seringa. [...] Ao encontrar a área que mais Ihes convinha, davam início à organização do seringal para montar a empresa extrativista. [...] A presença do seringalista e o conjunto de regras que estabelecia para o funcionamento da empresa extrativista faziam com que fosse reconhecido pelos seringueiros como o "patrão", a autoridade suprema naquela faixa da floresta (PAULA, 1991, p. 20). 
Empresários, donos de Casas Aviadoras, das cidades de Manaus e Belém, através do capital internacional, financiavam as atividades extrativistas na floresta acreana. Os trabaIhadores nordestinos foram atraídos para essa floresta, fugindo da seca e, com a promessa de enriquecimento, foram convertidos em seringueiros solitários, presos pelo inferno verde. Esses sujeitos foram inseridos no "centro" do sistema produtivo do seringal. Segundo Paula (1991, p.28), o seringal era organizado da seguinte forma: o dono do seringal era o seringalista e ficava na "margem"; residia geralmente nas beiras dos rios, onde havia um pequeno porto, com casas para o seringalista ou seu gerente e funcionários envolvidos em afazeres diversos, como os carregadores, caixeiros, guarda-livros, gerentes. Junto com essas casas ficava também o "barracão", local onde armazenavam as mercadorias, produtos para os seringueiros e estocavam a borracha por eles produzida. Depois essa produção era escoada pelos navios-gaiolas até Manaus e Belém do Pará. No barracão também se fazia toda a contabilidade da empresa; lá ficavam os livros de registro e a conta corrente do seringal. Os seringueiros residiam em pequenas palhoças, em colocações espalhadas pelos seringais. Eles faziam "limpeza das estradas de seringas (traçado geométrico que liga um determinado número de seringueiras), corte, faziam a colheita e a defumação" da borracha. A empresa extrativista também era composta por "mateiros", "toqueiros", "fiscais de corte", "noteiro" e "comboeiro".

O seringalista detinha plenos poderes na enorme área da floresta que estava sob seus domínios, podendo tanto premiar como castigar seus "fregueses" (seringueiros). Seu objetivo era obter a maior produção possível de borracha; não Ihe interessava o dispêndio de tempo e energia do seringueiro em outra atividade que não fosse a extração de látex. Era proibida a agricultura de subsistência. Com isso, o "patrão"(seringalista) assegurava, por um lado, um maior volume na produção de borracha e, por outro, garantia a manutenção dos laços de dependência do seringueiro, uma vez que todos os gêneros necessários à sua sobrevivência tinham que ser adquiridos no "barracão", sempre a preços exorbitantes (PAULA, 1991, p. 29).

O nordestino, declara Hardman (2009, p.69), "convertido em seringueiro anônimo nas florestas do Acre", chegava com uma dívida pelo transporte até a floresta. Lá, recebia os utensílios para fazer o corte da seringa, recebia também os alimentos para sua manutenção. Em troca, toda sua produção de borracha era entregue no barracão, onde ficava o patrão, para pagar sua dívida.

O "sistema de aviamento" estabelecia laços múltiplos de dependências, formando uma cadeia de dominação. [...] $\mathrm{Na}$ base de todo o funcionamento das relações mercantis estava o produtor direto, o seringueiro. A extração do excedente de seu trabalho realizava-se através da venda de mercadorias e da compra de produtos. A prisão pela dívida garantia a imobilização dessa mão de obra e constituiu-se em um dos traços marcantes da empresa extrativista. (PAULA, 1991, pp. 23,25)

Esse sistema de produção, de aviamento, foi cruel para com aqueles trabalhadores, pois, a cada ano, sua dívida só aumentava. Os preços dos gêneros alimentícios eram abusivos; a pesagem da borracha era quase sempre adulterada. Muitos desses seringueiros morreram na floresta. Alguns poucos conseguiram voltar para o Nordeste.

\begin{abstract}
O seringueiro é quase sempre um escravo das suas dívidas. Frequentemente se revolta e foge. Assisti a chegada de uma dúzia deles em Cruzeiro do Sul e fizeram uma detalhada exposição ao Prefeito. Um disse ter trabalhado para um mesmo patrão durante 12 anos, sem interrupção e ao invés de ver amortizada a sua dívida, no fim desse período, estava devendo-Ihe ainda 8 contos de réis. Outros se queixavam dos preços exagerados dos gêneros que lhes eram vendidos: um 'paneiro' (cesto) de milho que compravam por 60 mil réis, quando em Cruzeiro custava 12 (BARROS, 1993, p. 142).
\end{abstract}

Por outro lado, os seringalistas e seus financiadores ficavam cada vez mais ricos e incentivavam a busca de mais terras, para abrirem mais estradas de seringas, o que fez surgirem colocações de seringueiros por todos os rios acreanos. A única forma de comunicação com o resto do Brasil e o mundo era estabelecida via rios e se dava somente no período das chuvas, quando o volume das águas dos rios aumentava, permitindo a navegação dos navios, que traziam gêneros alimentícios, bebidas, tecidos etc. e escoavam a borracha até as cidades de Belém e Manaus.

Cunha (1976, p.132) observa: "O seringueiro é, obrigatoriamente, profissionalmente, um solitário". Estes trabalhadores isolados nos rincões da floresta, diante de uma natureza desconhecida, sem a presença da igreja, de médicos, recorreram aos índios para tratarem suas doenças com ervas, plantas medicinais e rezas, e também para obterem auxílio espiritual. Os seringueiros aprenderam com os nativos a sobreviverem na floresta e incorporaram à base de sua alimentação produtos da flora e fauna Amazônica, bem como modos, costumes e crenças indígenas locais.

O tempo áureo da borracha, para o Brasil, começou a findar por volta de 1913, após empresários ingleses e holandeses pegarem sementes das seringueiras brasileiras e fazerem plantio na Ásia, nos países: Ceilão, Indonésia e maciçamente na Malásia, com novas tecnologias e eficiência, aumentando sua produtividade. Começaram a colocar essa produção no mercado mundial, o que fez o preço da borracha cair, levando o extrativismo amazônico a entrar em uma forte crise, pois o sistema produtivo que se estabeleceu nessa região era desprovido de avanço tecnológico e de baixa produtividade.

Trinta anos antes do apogeu do ciclo da borracha, numa operação de contrabando à qual a lenda empresta lances de ação de espionagem, o aventureiro inglês Henry Alexandrer Wickham conseguiu uma 
partida de setenta mil sementes de seringueira e enviou-as para Londres. Plantadas experimentalmente em Kew Garden, as mudas foram transferidas, para o sudeste da Ásia, região da faixa equatorial e com clima semelhante ao amazônico. As mudas cresceram, transformaram-se em seringais ordenados como um bosque europeu e começaram a produzir (SOUZA, 2001, p.190).

Segundo Paula (1991, p. 31), o impacto que se fez na região gerou certa desarticulação no sistema de aviamento. A dificuldade em abastecer os "barracões" fez os seringalistas incentivarem os seringueiros a perpetrar uma agricultura de subsistência, dessa forma, muitos seringueiros se deslocaram para as margens dos rios.

Entre o período de 1920 a 1940, auge da crise da borracha, houve significativas mudanças para os seringueiros: os "barracos" deixaram de ser o único local de comércio e eles passaram a comercializar também com os regatões (espécie de comerciante ambulante, que desenvolvia seus negócios através de barcos por rios e igarapés amazônicos). Os seringueiros intensificaram a caça de animais silvestres, com o intuito de extrair a carne para sua alimentação e extração de peles, visando o comércio externo, pois o produto alcançava bons preços. A castanha amazônica também passou a ser coletada e exportada com bons preços no mercado internacional (PAULA, 1991).

Um dos artifícios utilizados para subverter a vigilância e o monopólio do patrão era a venda subreptícia do produto ao regatão [...] porque via nele não apenas a forma de satisfazer suas necessidades e pequenas vaidades $[\ldots]$ mas principalmente para vingar-se de alguma forma do patrão (MARTINELLO, 1988, p. 265).

Durante a segunda guerra mundial (1939 - 1945), os japoneses, aliados à Alemanha e à Itália, conquistaram o sudeste asiático, área produtora de borracha para os países aliados: Inglaterra, França e Estados Unidos. O governo Brasileiro assinou acordo com os Estados Unidos através do "tratado de Washington" para reativar os seringais nativos amazônicos e fornecer borracha para esse eixo, o que fez o Acre receber um novo alento de pessoas vindas do nordeste brasileiro, novamente aquecendo a economia da borracha. Esses trabalhadores passaram a ser denominados de soldados da borracha, pois foram alistados como voluntários de guerra para extração da borracha amazônica. Foram recrutados trabalhadores urbanos que atuavam na construção civil, na indústria têxtil entre outros setores e pequenos proprietários de terras. Muitos deles eram alfabetizados e tinham experiência em movimento sindical (MARTINELLO, 1988).

A entrada desses novos migrantes no território acreano criou condições favoráveis para modificar o comportamento do seringueiro frente ao patrão seringalista. O que nos indica esse fato é que os conflitos passam a ser cada vez mais frequentes a partir desse período (PAULA, 1991, p. 36).

Com o final da Segunda Guerra Mundial, em meados da década de 1940, novamente os seringais asiáticos foram retomados do Japão. Depois veio a borracha sintética, produzida a partir de restolhos do petróleo, o que levou novamente os seringais nativos amazônicos a entrarem em colapso, pois o mercado interno brasileiro não conseguia absorver toda sua produção.

Nos anos de 1950 a 1970 os seringueiros acreanos sofreram novas conjunturas em sua constituição identitária. O governo local do território do Acre criou colônias agrícolas nas proximidades de algumas áreas urbanas, para alojarem os seringueiros que saíssem dos seringais, com o intuito de fazê-los produzir alimentos voltados para o consumo da população acreana. No início dos anos 60 começam a surgir rodovias, facilitando a comunicação entre as áreas. Surge a figura do "marreteiro", que passa a estabelecer comércio ambulante com os seringueiros, disputando espaço com os "barracões" e os "regatões". O rádio começa a se expandir nos seringais, de forma que o seringueiro passa a ficar informado dos preços da borracha no mercado nacional. Isso fez o seringueiro exigir dos seringalistas melhores preços para a produção de sua borracha (ALLEGRETTI, 1979).

Nas décadas de 1970 e 1980, a região amazônica foi alvo de uma política de expansão e ocupação territorial pelo Governo Militar, que incentivou a migração massiva de pessoas do centro Sul e Sudeste do Brasil para a Amazônia, facilitando a compra de terras na região da floresta, para formarem fazendas de gado. Essa política desenvolvimentista trouxe sérios problemas para a região. Com a transformação da floresta em fazendas, iniciou-se a devastação e milhares de quilômetros de mata virgem deram lugar a pastos. Não se pensou nos homens que já moravam na mata: seringueiros sobreviventes dos ciclos da borracha e que permaneceram na floresta, com uma cultura extrativista e de subsistência. Centenas de famílias foram expulsas por estes "paulistas", como ficaram conhecidos os forasteiros. O destino deles, assim como o da floresta, foi trágico: seguiram para as cidades e se viram obrigados a se adaptar a uma nova realidade. Analfabetos e sem preparo para a mão de obra urbana, muitos caíram na marginalidade e foram viver nas áreas de periferia. Já outros foram para floresta boliviana, país vizinho ao Estado do Acre. Lá fixaram residência, fugindo da pressão que a chegada dos pecuaristas causou.

Em terras bolivianas, esses seringueiros continuaram seus modos peculiares de viver em harmonia com o meio ambiente. São, na grande maioria, extrativistas, praticam a agricultura de subsistência, criam pequenos animais, criam poucas cabeças de gado e vivem um modelo de vida que visa a preser- 
vação da floresta, um modo de vida quase autossustentável.

Recentemente, com a política nacionalista de Evo Morales, presidente da Bolívia, estes seringueiros se viram, mais uma vez, ameaçados de serem deslocados (ou expulsos?) das terras onde moram, agora pelos Bolivianos.

Há pouco tempo, toda a região da fronteira trinacional (Brasil-Acre, Bolívia-Pando, Peru- Madre de Dios) passava pela efervescência do discurso de integração, possibilitada pela construção da Rodovia Interoceânica. Uma das grandes contradições nesse processo de integração pelo qual passa a região instaura-se com a decisão, por parte das autoridades bolivianas, de expulsar os seringueiros brasileiros da faixa de $50 \mathrm{~km}$ de sua fronteira com o estado do Acre.

\section{O ATOR PLURAL NAS FRONTEIRAS DO BOLPEBRA: ANÁLISE E DISCUSSÃO DOS DADOS}

Metodologicamente, as falas dos seringueiros aqui avaliadas foram coletadas em vídeo. Tudo aconteceu no ano de 2006, quando foi realizada pesquisa de campo para gravar depoimentos de alguns desses seringueiros para a elaboração do documentário La rota del pacífico. Nessa ocasião, conheceu-se um seringueiro brasileiro, que vive em território boliviano, o qual serviu de guia, pelos varadouros e rios da Floresta fronteiriça boliviana, em dois momentos.

A primeira incursão na Fronteira ocorreu no mês de julho. Nesse período caminhou-se por quatro dias, numa trajetória de aproximadamente $80 \mathrm{~km}$. A segunda entrada na área aconteceu em novembro, ocasião em que se pôde descer o Rio Chipamano, que divide o território boliviano do brasileiro, e acompanhar o escoamento da borracha produzida para a cidade de Xapuri, no estado do Acre. Com o seringueiro guia ficou fácil chegar às colocações e ser recebido pelos outros seringueiros, pois com alguém deles apresentando o investigador, os seringueiros se sentiram mais confiantes em participar da pesquisa. Assim, entrevistaram-se 30 moradores e gravaram-se todas as atividades cotidianas que essas pessoas desenvolveram durante a estada na área.

A coleta dos depoimentos dos seringueiros aconteceu em um momento politicamente delicado. O clima por que passava a região, no momento da gravação, era tenso, pois o governo nacionalista de Evo Morales almejava fazer a reforma agrária na Bolívia e a solução encontrada foi expulsar os brasileiros que viviam na faixa de $50 \mathrm{~km}$ da fronteira com o Brasil, amparados pela constituição da Bolívia, a qual proíbe aos estrangeiros a posse de terras naquela faixa de fronteira.

Neste artigo, a partir de alguns depoimentos, busca-se verificar, à luz da teoria do ator plural, como os esquemas de ação desses sujeitos são representados diante da possibilidade de mudança de contexto em que vivem. Esse princípio teórico leva a verificar, então, nas palavras dos seringueiros, a pluralidade de esquemas de ações, que segundo Lahire (2002), constitui o ator.

Ao serem questionados sobre a ameaça de serem expulsos da Fronteira do BOLPEBRA, muitos seringueiros declaram não saberem se sobreviveriam longe das terras que habitavam.

\begin{abstract}
Se faltar hoje o que comer, assim... uma farinha, uma coisa, eu sei da onde eu vou buscar, eu vou buscar no roçado, eu vou buscar no mato uma carne de veado, de porco, de qualquer bicho, porque aqui, a gente se alimenta mais da carne da mata, a não ser quando mata um animal assim, e lá na cidade você chega com a família e não sabe o que fazer (grifos do autor). (Informação Verbal) ${ }^{2}$
\end{abstract}

Aqui, percebe-se que os esquemas de ação do ator seringueiro em relação à terra são pensados por ele apenas em um âmbito. $O$ seringueiro não se percebe capaz de transpor seus hábitos para outras dimensões. Ao seu ver, o deslocamento para a cidade provocaria o que Lahire (2002) denomina de desajustamento. Nesse sentido, a mudança de hábitos, de esquemas de ação provocaria um desconforto, sua existência se tornaria opressiva e pesada. Essas ponderações levam às reflexões de Lahire (2002, p.57), no tocante aos determinantes da ação, ao afirmar que "o comportamento de um ator é totalmente determinado socialmente", mas é impossível prognosticar tão facilmente o aparecimento desse comportamento. Isso ocorre não apenas porque as situações sociais são complexas, mas porque existe uma complexidade interna do ator cujo estoque de hábitos é mais ou menos heterogêneo. Nesse aspecto, Lahire (2002, p.58) propõe que é preciso considerar o contexto para que se possa avaliar "as disposições do ator em revelar um esquema de ação" ou outro em certas situações.

Assim, o seringueiro vê-se ameaçado diante da possibilidade de se distanciar da Fronteira, pois entende que a mudança de contexto social pode diluir aquilo que ele sabe fazer (seus esquemas de ação) e o que ele sabe fazer é a sua identidade. Nesse enunciado, o seringueiro parece acreditar que suas ações não podem se modificar, e isso pode estar relacionado ao fato de que não tem outras referências de ações em sua volta, já que, no espaço onde habita, não há outras possibilidades interativas para seguir. Mas Lahire (2002, p.59) pontua que as situações sociais, sejam as mais formais e institucionais, as mais informais, nas quais se vivem, são verdadeiros ativadores de resumos de experiências incorporados, que são os "esquemas de ação" (no sentido amplo do termo) ou os hábitos que se adquirem. O sujeito depende, assim, fortemente, desses contextos sociais (institucionais ou não institucionais) que retiram do indivíduo certas 
experiências e propiciam outras que ficam em estado de gestação ou de vigília, prontas a entrarem em cena. Ao mudar-se o contexto, quer profissional, conjugal, familiar, religioso ou mesmo político, mudam-se as forças que agem sobre o indivíduo, afirma o autor. Assim, mesmo temendo não sobreviver em outra situação, o seringueiro poderia identificar outros hábitos, novas identidades, caso mudasse de cenário social. Nas palavras de Lahire (2002, p. 59-60):

E se essas forças exigem de nós coisas que não podemos dar, então geralmente, não temos outras escoIhas senão encontrar uma outra maneira de continuar a viver - o menos mal possível - no mesmo contexto (adaptação mínima), mudar de contexto (fuga) ou transformá-lo radicalmente para que seja mais suportável (reforma ou revolução).

Destaca-se no depoimento anterior, ainda, o olhar que o ator lança sobre a cidade, descrevendo-a como um enigma, porque desconhece as formas de sobrevivência desse lugar. Ao nível do enunciado, o advérbio de lugar aqui - é o elemento que marca a aproximação que ele tem com a terra; ao dizer lá, o seringueiro instaura a cidade como o seu outro, o estranho àquilo que reconhece como seus esquemas de ação.

Esse ator parece não perceber que é portador de uma pluralidade de ações. Ao afirmar: "e lá na cidade você chega com a família e não sabe o que fazer...", o homem entrevistado demonstra ser plural, na medida em que se situa ora como pai de família, que precisa garantir o sustento da casa, ora como extrativista, que precisa da terra para sobreviver. Nesse sentido, a cena considerada é importante para verificar as variações de identidades que cada ator guarda em si. O segundo depoimento ressoa no mesmo sentido que o primeiro. Veja-se que após ser indagado sobre a possibilidade de sair do lugar onde vivia, responde:

O sonho da gente se acaba por aqui, meu amigo. Se for pra tirar a gente daqui, praticamente, não só o meu, que ainda sou um pouco novo, mas o que eu sei fazer é trabalhar no mato, é plantar um roçado, é cortar uma seringa, é abrir um roçado, é isso que a gente sabe fazer. (Informação Verbal) ${ }^{3}$

Ainda em se tratando de pluralidade de ações, nessa fala também repercute a noção de que os esquemas de ação dos atores seringueiros dizem respeito apenas ao universo agricultor, ao que eles fazem na e com a terra.

As condições sociais em que se inserem os atores determinam a homogeneidade ou a heterogeneidade quanto aos seus esquemas de ação congregados. Segundo Lahire (2002), independente do contexto em que se encontram os atores, o que determinará o seu comportamento é o modo como interage nele, imerso na heterogeneidade das relações sociais, nas sociedades contemporâneas, vividas em interações simultâneas por esses atores. $\mathrm{O}$ seringueiro, nesse depoimento, assim como no primeiro, pensa a mudança de suas ações pro- fissionais como uma missão quase impossível. Imagina que as disposições que incorporou ao longo de sua existência não podem ser ativadas em outros contextos.

Nesses depoimentos, percebe-se que as experiências do cotidiano, as ações das situações diárias vão construindo o olhar que os seringueiros têm sobre si e sobre o outro, um modo particular de lidar com sua realidade, enraizado nas práticas sociais coletivas da sua profissão.

No próximo item, traz-se um corpus distinto desse abordado até aqui. Selecionam-se algumas imagens que representam as ações dos seringueiros em cenas fotografadas. Essas imagens ajudam a refletir sobre a pluralidade desses atores que vivem na Fronteira do BOLPEBRA, na medida em que configuram, na dimensão visual, de que forma o cotidiano dessas pessoas é diversificado e às vezes até paradoxal. Para tanto, mobilizam-se não apenas a teoria do ator plural, mas, também, reflexões em torno da globalização, no intuito de se compreender a complexidade que envolve os esquemas de ação dos seringueiros no BOLPEBRA.

\subsection{A pluralidade do ator seringueiro: outras cenas}

Para Lahire (2002), no estudo dos esquemas de ação incorporados, podem ser consideradas as diferenças entre os tipos e dimensões da ação e tipos de atores, já que os momentos da vida em que se formam os diversos repertórios de hábitos são diferentes. Portanto, cada ator agirá mobilizando seus esquemas de ação conforme a lógica na qual foram agregados e a interação com a situação presente em razão da sua função "ativadora", "mobilizadora" desses esquemas. Sendo assim, destaca-se a importância de observar o ator em ação e daí compreender os efeitos das interações deste, nos contextos vividos.

No documentário La Rota Del Pacífico captam-se entre os seringueiros moradores da região denominada BOLPEBRA as contradições de um processo de intercâmbio cultural entre as nações que integram essa Fronteira. As observações in loco e as imagens captadas da Fronteira do BOLPEBRA revelam que esses atores estão localizados em um tempo e um lugar distantes dos processos típicos de sociedades consideradas desenvolvidas, conforme as imagens abaixo sugerem.

No cotidiano desses seringueiros, as embarcações, ainda rústicas, promovem o transporte e as travessias. O arroz é também rusticamente processado, por meio do pilão, para o consumo, o que sugere que a industrialização dos alimentos ainda é muito distante da realidade local.

Entretanto, pela observação in loco, constatou-se que os seringueiros brasileiros, esses mesmos moradores da área fronteiriça 
de Pando-Bolívia, Acre-Brasil, que sofrem o abandondo das autoridades brasileiras e bolivianas, que os negam o direito à cidadania, o direito à educação, à saúde, também sofrem o reflexo do processo de mundialização, através do consumo dos produtos mundializados, tais como calças jeans, televisores de marcas multinacionais, alimentados por energia solar, ou de motor tocado por óleo diesel, de produtos e marcas com nomes conhecidos mundialmente comprados nas cidades acreanas ou bolivianas, conforme observado na pesquisa in loco. Essa pluralidade social remete a uma discussão muito antiga dentro das ciências socias - a globalização.

Nesse aspecto, citamos Bauman (2005, P. 11), o qual considera a globalização (e o surgimento da "modernidade líquida") como: "[...] grande transformação que afetou as estruturas estatais, as condições de trabalho, as relações entre os estados, as subjetividades coletivas, as relações entre o eu e o outro, o colapso do estado de bem-estar social, a insegurança".

Na globalização, afirma Bauman (2005), está a resposta para a grande mudança pela qual passa o mundo. Essas mudanças, em vários setores da sociedade, além do colapso de algumas outras, podem ser justificadas pela "liquefação" das relações sociais por que passa o homem moderno. Dessa forma, o sociólogo enxerga a identidade como deslocamento, desterritorialização "(...) nessa época líquido-moderna, o mundo à nossa volta está reparti-

Figura 1 - Ribeirinho escoando sua produção

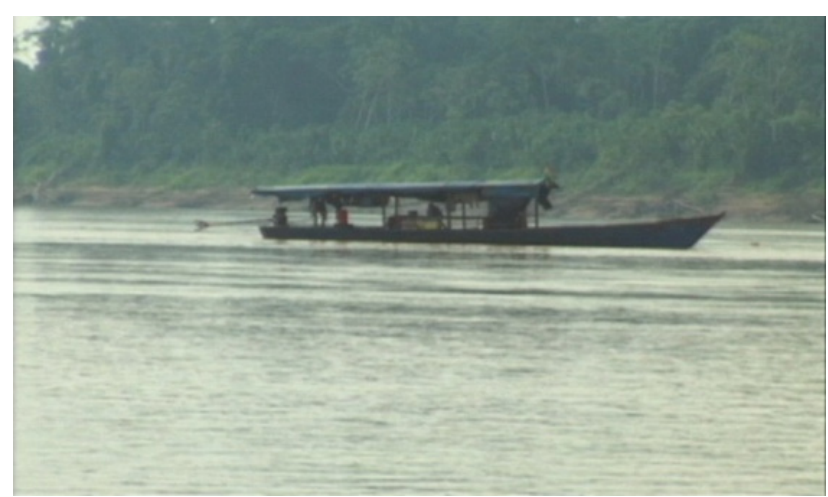

Fonte: Elaborado pelos autores

Figura 2 - Casal pilando arroz

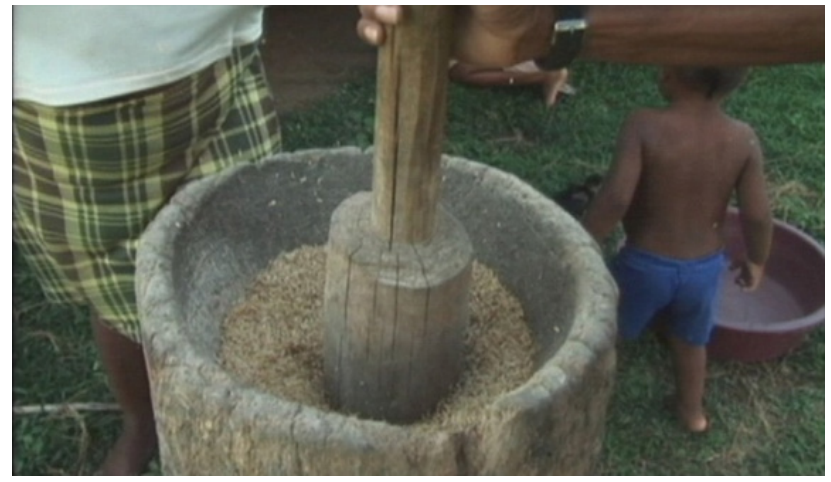

Fonte: Elaborado pelos autores do em fragmentos mal coordenados, enquanto as nossas existências individuais estão fatiadas numa sucessão de episódios fragilmente conectados" (BAUMAN, 2005, p. 18).

Consequência dessa instabilidade, para o autor, é que todos pertencem a várias comunidades e têm, por isso, várias identidades. Elas flutuam - algumas, de próprias escolhas, outras impostas. "Sentir-se em casa" exige um preço considerado alto a fim de constituir o "eu postulado" e tudo isso se dá porque "somos líquidos", ou seja, não há uma identidade única (BAUMAN, 2005, p. 21).

O temor dos seringueiros em não conseguirem desenvolver novos esquemas de ação é, pois, pouco provável de acontecer. Nesse sentido, a pesquisa de campo, as imagens captadas sugerem que os esquemas de ação dos seringueiros da área fronteiriça são muito mais plurais do que eles imaginam, do que eles percebem e afirmam em seus depoimentos. Essa pluralidade inclusive, pode-se dizer, constitui uma das grandes marcas desse povo, inscrito em um lugar e em um tempo em que as flutuações de contextos refletem novas formas de atuação e, portanto, de atores.

\section{CONSIDERAÇÕES FINAIS}

Este trabalho teve como aporte teórico-metodológico a Teoria da Ação proposta por Bernard Lahire (2002). Essa teoria permite analisar a pluralidade de esquemas de ação incorporados pelos sujeitos. No caso desta pesquisa, ela permitiu objetivar, ainda que superficialmente, a pluralidade de esquemas de ação incorporados pelos seringueiros do BOLPEBRA e a complexidade do seu engendramento.

Selecionaram-se e analisaram-se alguns depoimentos para avaliação de seus comportamentos observáveis e as elaborações narrativas de situações vivenciadas por eles, em seu cotidiano. Para tanto, foi necessário ouvi-los e acompanhá-los em seu dia-a-dia, utilizando a filmagem.

A priori, pode-se inferir que o processo de migração dos povos de um país para outro faz com que os indivíduos transformem-se em outros sujeitos, outros atores, e até construam nesse novo espaço uma nova identidade. Contudo, observou-se que os seringueiros não alteraram seu modo de vida após transporem as fronteiras nacionais, mas se deslocaram para garantirem a continuidade de seus hábitos e costumes ameaçados no Brasil.

Os dados coletados mostram que os seringueiros não se percebem como capazes de atuarem em novas cenas, diante da ameaça de perderem suas terras. Os relatos indicam que o sujeito não age sempre com coerência, dado a possível diversidade de elementos incorporados em razão da pluralidade de suas experiências socializadoras. A pluralidade nas relações sociais possibilita uma multiplicidade de esquemas de ação incorporados. 
Lahire (2002) aponta para a relação de homogeneidade e heterogeneidade dos contextos vividos pelo indivíduo ao longo da vida, entendendo que o contexto tem importante papel para ativação ou inibição de esquemas de ação incorporados. Sendo assim, a pluralidade dos atores aqui avaliados pode brotar dos vários esquemas de ação desencadeados a partir das condições de heterogeneidade vividas por eles, em contextos diversos. É importante observar que em cada contexto que esses atores se inserirem um novo esquema de ação será constituído.

\section{NOTAS}

1. Na ocasião, ganhamos um prêmio pelo projeto DOCTV 3 - programa de fomento à produção e teledifusão do documentário brasileiro, promovido pela Secretaria do audiovisual do Ministério da Cultura, Fundação Padre Anchieta/ TV Cultura e Associação Brasileira das Emissoras Públicas.

2. Entrevista cedida aos autores

3. Entrevista cedida aos autores

\section{REFERÊNCIAS}

ALLEGRETTI, Mary Helena. Os seringueiros: estudo de caso em um seringal nativo do Acre. 1979. 188f. Dissertação (Mestrado em Antropologia) - Universidade de Brasília, Brasília, 1979.

BARROS, Glimedes Rego. Nos confins do extremo oeste. Rio de Janeiro: Biblioteca do Exercíto, 1993.

BAUMAN, Zigmunt. Identidade: entrevista a Benedetto Vecchi. Tradução Carlos Alberto Medeiros. Rio de Janeiro: Jorge Zahar, 2005.

CASTRO, M.H.M. Amazônia: soberania e desenvolvimento sustentável. Brasília: Confea, 2007.

CUNHA, Euclides Rodrigues Pimenta da, 1866-1909. Um paraíso perdido: reunião dos ensaios amazônicos [por] Euclides da Cunha.
Petrópolis: Vozes; Brasília, DF, INL, 1976.

DOMINGUES, José Maurício. (Org.). A Bolívia no espelho do mundo. Rio de Janeiro: editora UFMG, 2009.

FRANCE, Claudine de. Cinema e antropologia. Campinas: Ed. UNICAMP 1998.

HARDMAN, Francisco Foot. A vingança da Hileia: Euclides da Cunha, a Amazônia e a literatura moderna. São Paulo: Ed. UNESP, 2009.

HOBSBAWM, Eric J. Nações e nacionalismo desde 1780. Rio de Janeiro: Paz e Terra, 1990.

LAHIRE, Bernard. Homem plural: os determinantes da ação. Petrópolis: Vozes, 2002.

LA ROTA DEL PACÍFICO: Culturas de Fronteira. Direção e Produção: Emilson Ferreira, Rio Branco: Projeto DocTV3, 2007. Documentário (51 min).

MARTINELLO, Pedro. A batalha da borracha na Segunda Guerra Mundial e suas consequêcias para o vale amazônico. In: Rio Branco: Universidade Federal do Acre, 1988. (Cadernos UFAC: estudos e pesquisas, 1 ).

PAULA, Elder Andrade de. Seringueiros e sindicatos: um povo da floresta em busca da liberdade. 1991. 256 f. Dissertação (Mestrado em Desenvolvimento Agrícola) - Universidade Federal Rural do Rio de Janeiro, Seropédica, 1991.

PESAVENTO. Sandra Jataí. Além das Fronteiras. In: MARTINS. Maria Helena (Org.). Fronteiras culturais. Porto Alegre: Ateliê Editorial, 2002.

SOUZA, Márcio. Breve história da Amazônia. 2.ed. Rio de Janeiro: Agir, 2001.

TOCANTINS, Leandro. Estado do Acre: geografia, história e sociedade. Rio Branco: Tribunal de Justiça, 2003.

VALCUENDE, Jose Maria. História e memórias das três fronteiras. São Paulo: Educ, 2009. 